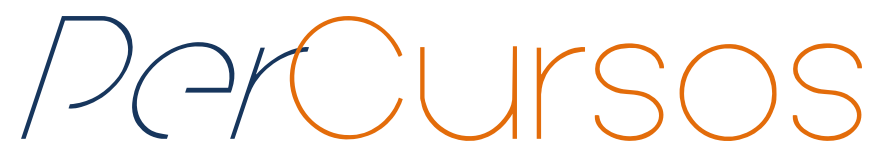

\title{
A educação Rural em Portugal - entre a aldeia e a escola ${ }^{1}$
}

\begin{abstract}
Resumo
O trabalho discorre sobre a vida de António Sérgio, pedagogo português que viveu entre os anos de 1883 e 1969, vivenciando diferentes momentos políticos, sociais e econômicos em seu país. Seu pensamento foi bastante expressivo no que tange à "educação pública para todos" em Portugal. Destarte, optamos em fazer uma pesquisa bibliográfica tomando como referência seu livro "Educação Cívica" escrito em 1915, quando mobilizado pelas ideias de educação popular da época, tratou da instrução pública para os povos das aldeias que, no início do século XX, constituíam a maioria da população portuguesa. Para adensar a pesquisa, nos apropriamos de outro livro "Manual de instrução agrícola na escola primária" que traz trazem importantes complementações no que trata à educação do povo, especialmente à educação rural. Empenhado na tentativa de trazer a escola ao mundo do trabalho, pretendemos analisar neste artigo quais foram as intenções de António Sérgio naquilo que alude à educação das pessoas que viviam em contextos isolados, distantes dos maiores centros urbanos de Portugal. Para Sérgio, as aldeias foram abandonadas pela riqueza dos descobrimentos durante os anos que marcam o início da modernidade, quando os filhos de lavradores começaram a fugir para a cidade. Uma condição que fora fracassada após a Independência do Brasil na América, quando as minas de ouro foram perdidas e então era preciso recuperar as minas da casa e fazer as terras de Portugal produzirem.
\end{abstract}

Palavras-chave: Educação rural. António Sérgio. Portugal.

\author{
Alcione Nawroski \\ Doutora em Educação pela \\ Universidade Federal de Santa \\ Catarina - UFSC. Atualmente \\ realiza estágio pós-doutoral na \\ Universidade de Varsóvia/Polônia \\ pelo Programa de Pós-doutorado \\ no exterior/Capes/Brasil. \\ Brasil
}

alcione.nawroski@ufsc.br

\section{Para citar este artigo:}

NAWROSKI, Alcione. A educação Rural em Portugal - entre a aldeia e a escola. Revista PerCursos, Florianópolis, v. 20, n.43, p. 195 - 214, maio/ago. 2019.

\section{DOI: $10.5965 / 1984724620432019195$}

http://dx.doi.org/10.5965/1984724620432019195

\footnotetext{
${ }^{1} \mathrm{O}$ artigo é resultante do estágio de doutorado sanduiche realizado pelo Programa Erasmus Mundus LINDO na Universidade do Porto/Portugal durante o ano letivo de 2015/2016 sob a supervisão da Prof. ${ }^{a}$ Dra. Sofia Marques da Silva.
} 


\title{
Rural education in Portugal: between the countryside and the school
}

\begin{abstract}
The work focuses on the life of António Sérgio, a Portuguese pedagogue who lived between 1883 and 1969, going through different political, social, and economic moments in his country. His thinking was always quite expressive regarding "public education for all" in Portugal. Therefore, we chose to do a bibliographical research, taking as main reference his work "Educação Cívica", written in 1915, when motivated by the ideals of Popular Education, sought to deal with public education for the people of the countrisyde that constituted the majority of the Portuguese population in this period. However, we take other books as "Manual de instrução agrícola na escola primária" which bring important additions to the education of the people, especially rural education. Committed to bring the school to the working world, we intend to analyze in this article, what were the intentions of António Sérgio in what alludes to the education of people living in isolated contexts, far from the main urban centers of Portugal. For António Sérgio, the countryside was abandoned by the wealth of discoveries during the years that is, and now was need that land produce in Portugal.
\end{abstract}

Keywords: Rural education. António Sérgio. Portugal. 


\section{Introdução}

António Sérgio foi um pedagogo português que viveu entre os anos de 1883 e 1969 vivenciando os diferentes regimes de Governo - Monarquia (até 1910); Primeira República (1910-1926); Ditadura (1926-1932) e o Estado Novo (1933-1974). Neto e filho de militares, nasceu na Índia Portuguesa e passou uma parte da sua infância no continente africano. Filho das grandes navegações, como fazia questão de dizer, não condenou o período do comércio marítimo como catastrófico, mas aproveitou para fazer uma análise bastante precisa deste período, onde levantou alguns dados sobre a história de Portugal.

Passados os tempos da infância na África, foi residir definitivamente com sua família na capital portuguesa onde estudou no Colégio Militar de Lisboa e, em seguida, ingressou na Marinha de Guerra permanecendo até o final da Monarquia. Na altura dos 27 anos de idade, quando foi implantada a República, António Sérgio abandonou a Marinha para, segundo suas próprias palavras, citadas por Gonçalves, “"manter a liberdade crítica e me dedicar à vocação que me parecia a minha: ensinar o povo a governar-se a si mesmo, graças a métodos de educação modernos e a novas praxes sociais-econômicas"” (SÉRGIO, 1915, apud GONÇALVES, 2003, p. 18).

Defensor de duas grandes ideias, a saber, o cooperativismo e a educação cívica, buscou correlacionar a política com a pedagogia visando o desenvolvimento e progresso de seu país. Desta forma, buscamos neste artigo desenvolver uma análise sobre o que o educador pensou a respeito da instrução pública para os povos das aldeias que constituíam a maioria da população portuguesa, no início do século XX. Para tanto, adotamos como metodologia de investigação, a pesquisa bibliográfica, aquela que nas palavras de Gil (1999) está constituída de livros e artigos, tendo como principal referência sua obra “Educação Cívica”, publicada em 1915. Por fim, para complementar e adensar esse trabalho de investigação, nos apropriamos de outros dois livros que são, "Manual de instrução agrícola na escola primária" e "A Sketch of the History of Portugal”, cujos quais trazem importantes complementações no que se refere à educação do povo, especialmente à educação rural. 
Após a Proclamação da República, António Sérgio passou a dedicar-se ao pensamento livre, resultando cinco anos mais tarde, aos 32 anos de idade, na publicação de uma das suas mais importantes obras que demarcaram as suas principais ideias a respeito da educação pública, sendo aprofundadas no decorrer da sua trajetória intelectual. Passados os primeiros anos da República Portuguesa, o autor teceu críticas a essa forma de governo, pela sua incapacidade de fundamentar os alicerces da democracia. Segundo Gonçalves (2003), para Sérgio, o republicanismo emocional e romântico deveria ser substituído tacitamente pela democracia, reformadora e concreta. Na obra, "Educação Cívica”, o autor fez uma descrição geográfica referenciada com dados econômicos para apresentar os fatos históricos e, por conseguinte, salientar que, após o período das grandes navegações e, posteriormente, a Independência do Brasil, Portugal precisava organizar sua metrópole para uma autossuficiência que deveria ocorrer pela mudança das condições jurídicas da sua produção econômica.

Para Pintassilgo (1998), entre os pedagogos portugueses, António Sérgio foi, no Portugal Republicano, o maior propagandista da necessidade de conectar a escola ao mundo do trabalho, ou, segundo Nóvoa (2004), a escola do trabalho é uma referência essencial, acreditando assim ser a mais importante do ideário sergiano em Portugal. Para Sérgio (2015), a educação e a economia eram concebidas pelas ideias de uma moral capaz de formar para o trabalho e, portanto, deveriam ser mentalizadas cotidianamente pelas pessoas. Dizia o educador: “Entendamo-nos: não vos peço ideologias, ou modernismos na política; peço-os na educação e na economia; na concepção da moral e do trabalho, na mentalidade das pessoas" (SÉRGIO, 2015, p. 25).

\section{A educação no Portugal rural}

Quando Sérgio lançou a obra “Educação Cívica”, em que preconizou a ligação da escola com as atividades produtivas do seu país, ressaltou a pedagogia como uma condição emergente de salvação do povo, em que a escola deveria instruir os rudimentos técnicos agrícolas ao pequeno agricultor. Segundo o autor, um ensino que pode ser simples e acontecer nas hortas escolares. Foi com essa ideia que solicitou a um 
engenheiro agrônomo a elaboração do "Manual de Instrução Agrícola para a Escola

Primária" no qual fez as seguintes advertências pedagógicas, durante a apresentação do referido manual:

É indispensável que o cultivador receba pelo menos os rudimentos de instrução escolar e técnica, à falta de exemplo e direcção de grande proprietário. É em Portugal a instrução deficientíssima, e o ensino agrícola elementar quase nulo. Neste país, em que é rara a grande indústria, alguma coisa se fez para instruir os jovens ricos, que aliás pouco aproveitam; mas o pequeno agricultor, que ocupa a mór parte do território, foi deixado ao abandono. Nada Ihe ensinam o Instituto de Agronomia de Lisbôa, com seus laboratórios e aulas teóricas, nem a Escola Agrícola de Coimbra, com seu esplendido campo, suas colecções e seu material. O de que carece é de hortos-escolas com ensino muito simples, muito practico, situado nas diferentes regiões do país. (SÉRGIO, 1916, p. 59-60)

O autor enfatizou a importância de uma educação técnica para o pequeno agricultor que era o responsável pelo cultivo da terra na maior parte do país, no início do século XX, e ao mesmo tempo era desprovido de qualquer conhecimento produzido nas instituições de ensino. Sérgio levantou a necessidade de uma educação popular ao apontar que a população das aldeias em Portugal foi abandonada pela riqueza dos "descobrimentos" durante os anos marcados pelo início da Modernidade, quando os filhos de lavradores começaram a migrar para a cidade. Uma realidade que foi sendo subvertida, principalmente com a Independência do Brasil, quando as minas de ouro foram perdidas e então era preciso recuperar as minas da casa, isto é, fazer as terras de Portugal voltarem a produzir. Preocupado com o progresso de seu país e, por conseguinte, com a educação do seu povo, Sérgio salientou na introdução do "Manual de Instrução Agrícola para a Escola Primária" que a escola primária rural será somente profícua quando conseguir fazer a criança se interessar pela vida do campo e amar a terra de forma inteligente.

Em 1640, Portugal perdeu o comércio do Oriente para Holanda e Inglaterra, mas ficou com o Brasil onde, diferente da América do Norte, a qual também recebia levas de colonos expatriados, o negro foi a principal força braçal de ocupação portuguesa. A 
exploração das minas e o comércio com os holandeses e ingleses manteve a Monarquia Portuguesa fortalecida por um longo período, enquanto a educação caía no parasitismo, temendo a Companhia de Jesus que tinha realizado a implantação de um sistema de educação, mas que não convinha mais ao momento histórico que o país vivia (SÉRGIO, 1928).

Quando Portugal perdeu a mina do Brasil $^{2}$, o país precisava urgentemente buscar por uma outra mina e que nessas alturas teve dificuldade de encontrar. Entretanto, Sérgio apontou o trabalho braçal como a estratégia primordial para levantar riquezas. Mas, como isso pode ser possível se a nação por tanto tempo "fôra o comunismo da ociosidade?" (SÉRGIO, 2016, p. 51). Sob uma outra ótica, refutando as ideias de António Sérgio, Hespanha atribui a crise das famílias camponesas na segunda metade do século XIX à emergência da propriedade capitalista, quando:

As famílias camponesas, privadas dos recursos da economia moral aldeã, ficaram indefesas perante a agressividade das novas estruturas capitalistas e foram entrando, aos poucos, na esfera das suas relações. $O$ salário industrial passou a comandar o cálculo econômico das famílias, na medida em que, sem ele, a reprodução econômica ficaria comprometida. Uma parte crescente da população camponesa estava condenada a escolher entre uma condição semiproletária, com trabalho fora ou indústria a domicílio, e a saída para a emigração. (HESPANHA, 1994, p. 81)

O sistema capitalista chegou ao campo, mas ainda não trouxe consigo a escola. Pois, o acesso à escola ainda não estava acessível aos camponeses das aldeias, tendo em vista que ainda predominavam as aspirações da hegemonia jesuítica. Segundo Sérgio, mesmo com a expulsão dos Jesuítas de Portugal e das demais colônias, por Marques de

\footnotetext{
${ }^{2}$ The declaration of the Independence of Brazil in 1822, was an event that was to have the graves of consequences for the mother-country, inasmuch as it shook to its very foundations the whole economic structure of Portugal. The general commotion produced in the country by the passing of the Constitutional Act, immediately before, was nothing to the commotion that now ensued. [...]. Now, however, things were different, and Brazil either had again to become a colony or else the very structure of the Portuguese nation had to undergo a complete change. Conservative Portugal rose, therefore, in unison, against D. Pedro and his allies, the Liberals (SÉRGIO, 1928, p. 149-150).
} 
Pombal, a educação continuava a ser a mesma, formando um mar de doutores, impróprios para o trabalho e o progresso do país:

O certo é que a realidade pedagógica continuou sendo a do século XVIII no seu espírito e objectivo: fazer escribas, desembargadores e rimadores; e por falta de uma escola de trabalho, a nação atolou-se nos empréstimos e envolveu-se em lutas políticas cuja mola fundamental era o assalto ao emprego público. (SÉRGIO, 1916, p. 52)

Assim sendo, o país continuava a viver às expensas de recursos alheios que não eram frutos nem do seu trabalho, nem da sua economia. O autor teceu uma forte crítica ao costume que os portugueses tinham de recorrer ao Estado para resolver os seus problemas, cuja atitude chamou de "comunismo de Estado". Por fim, reforçou que essa era uma prática instituída pela educação portuguesa de raízes jesuíticas que formavam bacharéis burocratas com fome de emprego público, incapazes de tocar a vida de uma forma independente. Semelhante prática foi identificada nos escritos de um educador brasileiro - Antônio Carneiro Leão (1939, 1946), para quem as experiências de institucionalização da educação foram parecidas no Brasil quando os filhos de latifundiários almejavam por seus diplomas de bacharéis, especialmente em direito, na Universidade de Coimbra, de Salamanca e na Sorbonne para, futuramente, se esbarrarem nos corredores das instituições públicas.

Ao pensar uma reforma da nação em prol do progresso, o educador português destacou a questão da agricultura e a falta de um sistema de irrigação para o aproveitamento das águas, também salientou o florestamento, a criação de energia hidroelétrica, crédito agrícola, estabulação de gado, aproveitamento dos detritos orgânicos, "derramamento da instrução agrícola, organização do ensino na escola primária, em torno do trabalho da agricultura como 'centro de interêsse' para toda a instrução" (SÉRGIO, 1932, p. 294).

Além disso, o povoamento e a colonização do país precisavam acontecer "segundo um regime cooperativista; e se fôr por iniciativa particular - tanto melhor" (SÉRGIO, 1932, p. 308). Mas, que tenha sobretudo o sentimento da igualdade cívica. O 
cooperativismo é outro tema bastante recorrente em suas obras, tendo em vista que o educador aposta numa educação cívica por meio das relações cooperativistas dentro das escolas a que, em dado momento, chama de escola-município quando, na visão do educador, os estudantes deveriam se auto organizar nas escolas da mesma forma que estão organizados os autogovernos municipais.

António Sérgio assevera a crítica em relação ao modelo de educação que Portugal por tanto tempo vem reproduzindo, cujos moldes ainda são de uma herança jesuíta uma "educação pela palavra e pelo livro, que cultiva a memória e o palavrório" (SÉRGıO, 1916, p. 56), que não é capaz de instigar a “iniciativa, o método, a perseverança, o domínio de nós mesmos e o dos instrumentos de trabalho”. Para o educador, é preciso ensinar a nação portuguesa que não basta somente manejar a espada. Mas, "que os verdadeiros instrumentos de conquista são a charrua, o tear, o capital, e que um território só é nosso quando nele, muitíssimo mais que funcionários e soldados, há trabalhadores nacionais" (SÉRGIO, 1916, p. 57).

Sob a égide de um espírito nacionalista e progressista, o educador ressaltou a importância do trabalho dos professores, cuja função dos mesmos se redefine sob uma "nova mentalidade" capaz de dirigir, suscitar e sugerir problemas para que sejam resolvidos não pela transmissão da palavra, mas pelo manejo da realidade em que a educação precisa se integrar à economia local com a subvenção das indústrias. Ao apresentar alguns dados históricos, acrescentou que Portugal ainda é um país com poucas indústrias, portanto, é preciso instruir pelo menos os rudimentos da instrução escolar e a técnica ao pequeno agricultor que deverá ocorrer por meio da educação primária, até porque, como mencionou o autor, o Instituto de Agronomia de Lisboa e a Escola Agrícola de Coimbra não foram capazes de atender a demanda instrucional dos trabalhadores das aldeias.

Influenciado pelas ideias da Escola Nova, especialmente do estadunidense John Dewey, o pedagogo prezava por um ensino agrícola nas escolas primárias rurais que preparasse para a vida e fosse essencialmente intuitivo, concreto e experimental. Na obra publicada em 1913, "Da natureza da affecção", Sérgio delimitou a afecção por meio da psicologia experimental de Wundt sobre os processos representativos da sensação 
dividida em três estados de emoção que compreendem o núcleo psicológico, as sensações orgânicas de várias espécies como musculares e as sensações de agrado e desagrado (SÉRGIO, 1913). Dada a complexidade dos sentimentos que delimitam a afecção, o autor recorreu a outro inspirador da Escola Nova para reforçar que à escola deverá tratar das emoções nos seus diversos estágios em "que a espontaneidade é a qualidade primacial do homem e, muito mais ainda, da criança e do adolescente. Quereme parecer que matar a espontaneidade a fogo lento é um crime de lesa humanidade" (FERRIÈRE, 1928, p. 18). Assim, será preciso desenvolver o sentimento de afeto nas mais diversas dimensões que nos cercam a vida na aldeia, como a terra, a escola e o trabalho. Para Sérgio (1916, p. 65), “O ensino agrícola na escola primária rural só será realmente profícuo, se conseguir interessar mais a criança pela vida dos campos, a fizer amar mais inteligentemente o seu torrão, Ihe deixar entrever os largos horizontes".

\section{As estratégias pedagógicas como promotoras do desenvolvimento rural}

Para o pedagogo português, não era preciso aprender os ofícios da agricultura da mesma forma que se aprende o catecismo. Segundo ele, “o livro para a criança deve ser o campo, o jardim, a horta, a natureza enfim, onde ela largamente se pode habituar a observar, cabendo ao mestre a explicação das razões das cousas" (SÉRGIO, 1916, p. 66). A forma como o pedagogo expõe suas ideias a respeito das escolas agrícolas renega todo o passado escolar em que as escolas estavam fundamentadas num modelo de educação tradicional sistematizado pelos princípios da Companhia de Jesus, portanto, das antigas escolas de formação jesuítica que reproduzia uma educação para a criança e outra para o professor. Para o autor, não cabe mais o ato da transmissão de quem sabe para quem não sabe, mas de preparar para o trabalho por meio das situações cotidianas onde o campo é o principal livro didático a ser seguido, numa construção conjunta entre educador e educando:

O ensino agrícola na escola primária rural, sendo essencialmente intuitivo deve ter por fins principais desenvolver na criança amor inteligente pela 
vida do campo e, dando-lhe noções scientíficas do que observa despertar nela o desejo de alargar os seus conhecimentos. (SÉRGIO, 1916, p. 66)

Como uma forma de desenvolver o amor à terra, as visitas de campo deveriam ser práticas constantemente adotadas como uma estratégia pedagógica, principalmente nos períodos das colheitas:

As excursões, passeios ou visitas far-se-hão tantas vezes quantas fôr possível e preferivelmente nas ocasiões em que se executam os trabalhos agrícolas mais importantes de cada estação. Para destas excursões se tirarem bons resultados, o professor deve organizá-las antecipadamente e, antes de partir, fará conhecer aos alunos o fim delas. Deste modo excita-lhes a curiosidade e predispõe-os para melhor observarem. (SÉRGIO, 1916, p. 148)

António Sérgio foi além dos seus propósitos didáticos e elencou uma série de atividades a serem realizadas em todas as estações do ano, respeitando a sazonalidade da produção agrícola. Também propôs a criação de bibliotecas rurais, museus escolares e formas de correlacionar atividades agrícolas com os conteúdos das disciplinas na escola, pois a agricultura precisa constituir a base primeira de ensino nas escolas rurais. Como uma tendência do ensino moderno, Sérgio (1916) citou a regionalização que visa sobretudo a adaptação às circunstâncias locais e do meio. Em sendo assim, o professor deverá desenvolver atividades pedagógicas que envolvam a produção local, seja de pesca em regiões marítimas ou pomícolas, em regiões de fruticultura, trazendo os elementos regionais para dentro da sala de aula.

Ao pensar a escola, o educador português destacou a importância também de pensar nos bons métodos de ensino adotados e que dão certo, e isso não quer dizer que os pedagogos precisam ter domínio das boas teorias da educação, mas sobretudo serem pedagogos de pedagogia prática, aqueles que não são cientistas, mas professores que senhoreiem a técnica e os modernos processos de sua arte. Por fim, o autor ressaltou que as escolas em Portugal deveriam ter dois objetivos principais, resumidos em: "preparar o 
Cidadão e aperfeiçoar o Agricultor - educar para a Liberdade e para o Trabalho Cooperativo" (SÉRGIO, 1939, p. 22).

Vale destacar que a teoria do cooperativismo em Portugal foi elaborada por Sérgio pensando na população do seu país, predominantemente camponesa, durante os primeiros anos da República:

Grandissima parte das escolas são rurais, e a profissão agrícola é a mais importante (e por isso) de todas as profissões do nosso país; como são a agricultura e as pescarias o que mais nos convém desenvolver, - é para a escola rural, principalissimamente, que se devem voltar as atenções. Fazer o agricultor-cidadão; reformar os métodos do lavrador português, afazendo-o à prática do cooperativismo e ao hábito de submeter a actividade própria a um plano de trabalho colectivo, ao de intervir nos negócios da comunidade: tal deve ser o nosso intuito. (SÉRGIO, 1939, p. 24)

Ao revelar uma crítica às escolas tradicionais destacando como um problema aquilo que os estudantes aprendem de agricultura pelos livros e não pela terra, o educador buscou inspiração no historiador português Alexandre Herculano ${ }^{3}$ ao dizer que os livros podem ser os piores instrumentos para adquirir a instrução, tendo em vista a falta de uma atividade prática, a ser desenvolvida pela escola. Dessa forma, a crítica de Sérgio apontou que as instituições escolares em Portugal não estão preparadas para atender às necessidades emergentes levando em conta a realidade social do seu país, fomentada por uma agricultura frágil e uma indústria ainda incipiente.

\footnotetext{
${ }^{3}$ Alexandre Herculano (1810-1870) foi um escritor, historiador e jornalista português, um dos principais autores do Romantismo em Portugal. De origem humilde, estudou no Colégio dos Oratorianos entre os anos de 1820 e 1825. Não frequentou a universidade. Em 1830, fez um curso de Comércio e em seguida um curso de Diplomacia. Estudou francês, inglês e alemão. Envolvendo-se com as lutas liberais que se espalhavam pelo país, foi perseguido e obrigado a emigrar para a França. Nessa época, por meio de muitas leituras conheceu o romantismo dos escritores franceses. Quando regressou a Portugal alistou-se no exército de D. Pedro IV, participando de várias lutas. Em 1833, foi nomeado para assessorar o diretor da Biblioteca Pública do Porto, onde ficou até 1836. De volta a Lisboa, torna-se diretor e redator da revista "Panorama", onde publicou vários de seus estudos históricos, alguns contos e novelas, que foram posteriormente editados nos livros "A Voz do Profeta" (1836) e "A Harpa do Crente" (1838). Fonte: AA.VV., Alexandre Herculano. Ciclo de Conferências Comemorativas do I Centenário da sua Morte. 18771977, Porto, Biblioteca Pública Municipal do Porto, 1979.
} 
Para o pedagogo português, o cooperativismo é uma forma de emancipação do homem pela teoria econômica do homem produtor e consumidor sob a forma de um socialismo não estadualista, mas, "um socialismo para todos, acolhedor de todos, sem a mínima distinção de natureza política ou sociológica" (SÉRGIO, 1948, p. 12). Para tanto, os professores devem "treinar os jovens para o cooperativismo" (SÉRGIO, 1939, p. 28) por meio de experiências típicas, capazes de inquirir mais tarde quando queiram empreender algum trabalho. Insiste o pedagogo que: "O que vale é o treino cultural do aluno num verdadeiro exercício de explicação e de crítica, e não o que estampamos no cardápio" (SÉRGIO, 1939, p. 30).

A escola precisa manter a juventude das ideias e, para tanto, deve adotar a experiência como uma prática pedagógica inovadora: “A escola deve ser uma fonte de juventude, onde se vai beber para toda a vida o dom da constante renovação: educar uma criança é não deixar secar a argila: e por isso também, a primeira qualidade do educador é a juventude espiritual” (SÉRGIO, 1939, p. 15-16). Sérgio apostava na juventude do seus país por meio de uma juventude pedagógica em que as escolas deveriam inovar ao criar e estabelecer novas e diferentes propostas pedagógicas.

Ao reverberar a negação de um modelo tradicional de Educação Jesuíta e se mostrar a favor de uma escola laica, que estimule a formação para a vida, pode-se facilmente aproximar o pensamento de António Sérgio aos ideários da Escola Nova evidenciados na época de seus escritos. Segundo Dewey (1916), a educação é um "bringing up" que precisa ser compreendido como um processo em construção contínuo, constituído de determinados fatores de retroalimentação - fostering, nurturing, cultivating para que ela se torne efetivamente um ato significativo aos jovens. Nutrir e cultivar sentimentos de carinho e incentivo por aquilo que fazem, são necessários ao processo do ensino levantados por John Dewey e assim, Sérgio conseguiu, a seu modo, por meio das suas publicações e orientações, fazer da educação rural uma prática humanista envergada de sentido, à medida que alçava ideias de uma escola tomada pelo sopro da vida. 


\section{António Sérgio no Ministério da Instrução Pública}

Durante o período em que Antônio Sérgio foi Ministro da Instrução em Portugal, um período extremamente curto (entre 18 de dezembro de 1923 e 28 de fevereiro de 1924), o educador procurou, dentre suas principais ações, difundir os métodos de ensino de Maria Montessori e Jean-Ovide Decroly, com a criação do cinema educativo e do ensino especial para deficientes. Ao entregar a pasta ao futuro ministro, destacou que as coisas mais importantes no momento eram organizar a formação de professores e a organização das escolas experimentais. Também tinha iniciado um processo de convênio com outros países como França, Alemanha e Espanha para encaminhar jovens portugueses a fim de realizarem intercâmbios por meio da concessão de bolsas de estudos.

Durante a rápida passagem pela pasta da Instrução Pública, Sérgio tentou convencer o Presidente de Concelho a fazer algo pelo desenvolvimento de uma cooperativa escolar compreendida basicamente como uma associação sugerida pelos professores, mas auto gestada pelos estudantes. Uma associação que fosse "composta dos alunos, antigos alunos e amigos de uma escola, com o escopo principal de dotar esta última do material escolar e das instituições competentes para vitalizar e modernizar o seu ensino, e fomentar a atitude da solidariedade" (SÉRGIO, 1939, p. 54). Os recursos financeiros desse empreendimento deveriam ser oriundos do trabalho dos estudantes, pela venda dos produtos que produziam, seja no artesanato, na cozinha e no cultivo da horta escolar.

No entanto, essa proposta de educação não durou muito tempo, sendo interrompida em 1926, pela Ditadura Militar, quando o Estado retroagiu nos direitos conquistados e a educação voltou a ser segregada pela divisão de gênero. Durante o período da Ditadura Militar em Portugal, os princípios da educação se restringiram a ler, escrever e contar. Inúmeras mulheres professoras precisaram retornar ao papel tradicional da mãe, dona de casa e esposa. Sobre esse período histórico, Araújo (2000, p. 274) assevera que, “o professor deixou de ser 'o sacerdote da democracia’ para se tornar 
o "modelador de almas"', pois foi retirada a autonomia de pensar do professor, para apenas cumprir as ordens do Estado.

As escolas passaram a receber esporadicamente a visita de um inspetor que ocorria de tempos em tempos, dependendo da localização geográfica da escola. Sobre isso, Araújo, ao investigar a vida das professoras por meio de suas histórias, apresenta a narrativa da professora Tereza, bastante eloquente para ilustrar esse momento histórico:

Era um sábado e era suposto que as escolas primárias dedicassem algum do seu tempo a atividades relacionadas com a organização nacionalista da Mocidade Portuguesa e religião. $O$ inspetor visitou primeiro a escola dos rapazes, no rés-do-chão. Tereza podia ouvir da sua sala, no primeiro andar, que o outro professor tinha começado a rezar o terço, Tereza nunca rezou com suas alunas. Eu estava no andar de cima e nunca rezava com as alunas. Também não ia fazer isso, lá porque tinha a presença do inspetor no andar de baixo. Ouvia-se tudo, porque a escola era velha, $e$ havia grandes frinchas para o andar de baixo (fala da professora). Tereza sabia que estava numa situação delicada e difícil. Começou a falar aos alunos acerca da solidariedade. Em seguida, levou-os para o recreio para os jogos e ginástica, em vez das actividades da Mocidade Portuguesa. $O$ inspetor veio observar e, no fim dos jogos, felicitou-a. (ARAUJO, 2000, p. 304)

A professora Tereza não concordava com as práticas pedagógicas instituídas pela ditadura, entretanto, buscava à sua maneira subvertê-las sem que fosse de conhecimento das visitas esporádicas do inspetor. Araújo (2000), ao realizar sua investigação com mulheres que atuaram como professoras de escolas primárias em aldeias do norte de Portugal durante o início da Ditadura Militar, identificou que o analfabetismo dos camponeses aliado ao seu estilo rudimentar de vida, não possibilitava haver uma aproximação com o "capital cultural” das professoras. Portanto, o contexto social das escolas levava à sensação de total isolamento dos professores que lecionavam nas aldeias, pois eles não tinham com quem compartilhar suas preocupações e angústias de escola, tendo em vista que seus colegas de profissão se encontravam em aldeias afastadas em que a mobilidade de uma para outra era bastante defasada ou até inexistente. Por outro lado, como forma de suprir esse isolamento das escolas nas 
aldeias, António Sérgio, inspirado no ensino norte-americano fez a defesa de uma educação sob a organização do cooperativismo, capaz de reunir os estudantes das mais diversas aldeias em uma só, uma prática que nos Estados Unidos deu certo por conta da instituição do transporte escolar em áreas rurais.

\section{O cooperativismo em António Sérgio}

Em 1926, o Parlamento português foi deposto e o Presidente da República derrubado. Portugal passou a ser dirigido por um governo forte em que concentrava todos seus poderes em si. Tratava-se de um governo militar disposto a salvar a pátria, capaz de abolir as greves e a liberdade de imprensa. Em 1928, o professor da Universidade de Coimbra, Antônio Salazar assumiu as finanças do Estado e passou a controlar todos os ministérios, disciplinarizando a administração financeira. Antônio Sérgio, não concordando com o governo de Salazar, por isso foi perseguido e preso várias vezes.

Todas as propostas de ensino pensadas durante o primeiro Período Republicano foram censuradas e à escola foram atribuídos alguns dogmas, como: Deus, Pátria, Autoridade, Família e Trabalho. Segundo Nóvoa (1997), no período do Estado Novo, a educação escolar em Portugal foi reduzida à matemática, leitura e escrita. De modo geral, o ensino escolar ficou circunscrito às cidades de Lisboa e Porto, e os demais concelhos e aldeias ficaram desprovidos de qualquer benefício pedagógico.

Para Cunhal (1968), durante a primeira metade do século XX, Portugal ficou aproximadamente meio século atrasado em relação aos pequenos países de capitalismo avançado da Europa. Em relação aos panoramas de educação, Pintassilgo descreve dados mais atemorizantes apontando que o país, durante o início da República, ficou com mais de séculos de atraso em relação a outros países da Europa:

Porque se Portugal outrora assombrara o mundo com o impulso dado à civilização pelos seus audaciosos descobrimentos, pelas suas conquistas legendárias, presentemente vivia na mais humilde e deprimente condição: com o fanatismo religioso profundamente arraigado nas 
classes baixas, com o império colonial espoliado, com uma dívida nacional de oitocentos mil contos, com o comércio, a indústria e a instrução atrasadas quase séculos de outras nações, Portugal era positivamente a Turquia do Ocidente. (PINTASSILGO, 1998, p. 57)

Sob um Governo Ditatorial, a agricultura e a indústria no país passaram a se desenvolver por meio de recursos rudimentares levando Portugal a ocupar o último lugar da Europa Ocidental no que confere à utilização de tratores e adubos químicos para a produção dos principais produtos agrícolas. Cunhal (1968), destaca no final da década de 1960, que os países do sul que se destacam pelo brilho da luz do sol, são ao mesmo tempo os países que mantêm uma superpopulação latente no campo retratada pelos velhos processos de séculos passados em que a causa disso reside no desenvolvimento do capitalismo, acometido pelo aumento da riqueza e da produtividade do trabalho nos países do norte da Europa. Por fim, assevera que em relação a Portugal, “ninguém que tenha olhado com um mínimo de atenção e seriedade a situação dos trabalhadores do campo, pode negar a miséria, o desemprego, as doenças, a alta mortalidade infantil, o analfabetismo" (CUNHAL, 1968, p. 48).

Em relação aos modos de produção agrícola durante a primeira metade do século XX, no país do ocidente Ibérico, o trabalho mecânico era ausente e a produção ocorria da mesma forma que três séculos atrás, segundo um relatório realizado em Santo Tirso, na região norte do país:

o material agrícola é mau e as lavouras "superficiais e imperfeitas", semeia-se o milho a lanço, gastando quantidades desnecessária de semente e usa-se, na cultura de batata, semente excessivamente pequena e má, "rega-se mal", desperdiçando-se água, "utilizando-se água a temperaturas baixas e pouco batidas" e regando-se a horas do calor; as ceifas são sempre as foucinha mesmo quando "haveria vantagem em utilizar a gadanheira". (CUNHAL, 1968, p. 196)

Para o autor, a falta de aperfeiçoamento das técnicas agrícolas derivava dos poucos cursos de formação na área de ciências da terra, principalmente para trabalhar com os camponeses pobre. Assim, o camponês português com poucos hectares de terra, 
"não fabrica o vinho, vende as uvas ao industrial, impossibilitado como está, por falta de técnica" (CUNHAL, 1968, p. 198).

Além da pouca disseminação das técnicas agrícolas no Portugal rural como aqui salientamos, uma outra preocupação de António Sérgio era com a ocupação e o cultivo das terras, especialmente aquelas ainda improdutivas. Assim, inspirado nas ideias de Mouzinho da Silveira, um liberal que durante a Monarquia foi responsável pela Pasta da Fazenda e defendia a produtividade dos solos ao acreditar que todas as terras portuguesas deveriam ser cultivadas, Sérgio tentou apresentar um modelo de educação rural para o progresso do país. Inspirado nas ideias liberais, o educador demonstrou em "Educação Cívica”, algumas estratégias de educação para as escolas rurais, sinalizadas como eficientes durante a Primeira República ao preparar seus alunos para o trabalho por meio do self-government, como forma de fazer produzir os setores mais pobres do Estado português.

As ideias de António Sérgio nem sempre foram aceitas no que se refere ao desenvolvimento do país e à educação. Por outro lado, foi por meio delas que Sérgio deixou sua contribuição ao Pensamento Pedagógico Português levando em conta os aspectos da renovação pedagógica, especialmente aqueles discutidos entre os escolanovistas e o movimento de renovação da educação rural em Portugal.

Foi nesse contexto de precariedade que António Sérgio aperfeiçoou seus escritos a respeito do cooperativismo nas escolas, publicados pela primeira vez em meados da década de 1910, quando defendeu uma educação sob a organização do cooperativismo, capaz de reunir os estudantes das mais diversas aldeias. Uma prática que nos Estados Unidos funcionou como um modelo de referência por conta da adoção do transporte escolar em áreas rurais oportunizando a mobilidade dos estudantes. O cooperativismo foi pensado e desenhado pelo pedagogo como uma forma de vida, "uma estrutura social; como um sistema, uma solução, um ideal, um alvo, - um objetivo para todos, um ideal para todos, que a todos se dirige, que se não recusa a ninguém" (SÉRGIO, 1948, p. 10).

Ao defender o cooperativismo como uma estratégia de organização pedagógica das escolas, especialmente entre os jovens e adolescentes das aldeias - na faixa etária de 
12 aos 18 anos -, Sérgio (1948) também aspirava por meio de um espírito nacional, a organização cooperativa como uma forma de auto-organização dos camponeses nas aldeias. O educador viu na escola, um meio de aplicar no campo material da vida, os princípios da liberdade, igualdade e fraternidade. O educador acreditava que o cooperativismo poderia “derrotar os capitalistas no seu próprio campo, com as próprias armas do liberalismo econômico; nascer na matriz do regime oposto e substituí-lo um dia completamente, como fez o capitalismo ao regime feudal” (SÉRGIO, 1948, p. 27-28).

Antônio Sergio apontou o cooperativismo baseado na ideia norte-americana de school-city and self-government ${ }^{4}$ como forma de superar a miséria que o país vinha enfrentando. Contudo, para Cunhal (1968, p. 74), esse cooperativismo foi "meio pacato, calmo, inofensivo; um cooperativismo cuja maior utilidade é defender o regime de Lucro e entravar qualquer real movimento para uma 'modificação do regime social'”. Contudo, se as ideias de Sérgio contribuíram para uma renovação das ideias pedagógicas de Portugal, do ponto de vista especialmente econômico, aqui apontado por Cunhal, sua proposta foi pouco significativa para a vida dos trabalhadores agrícolas das aldeias.

\section{Considerações finais}

Da mesma forma que a Escola Nova está marcada no Brasil pelos nomes de Antônio Carneiro Leão, Lourenço Filho, Anísio Teixeira, entre outros, em Portugal foi marcada pelos nomes de António Sérgio, Adolfo Lima, Faria de Vasconcelos e Álvaro Viana de Lemos que buscavam conhecer as ideários da Escola Nova para a renovação do Pensamento Pedagógico tanto no Brasil quanto em Portugal, respectivamente. Contudo, são ideias que hoje possibilitam traçar aproximações sobre o pensamento educacional entre os dois países num mesmo período histórico, aproximando os ideários pedagógicas no que consiste a uma proposta de modernização da educação rural.

\footnotetext{
${ }^{4}$ A verdadeira educação nacional seria a urgente educação anglo-saxônica, adaptada a uma escola do trabalho e da organização social do trabalho. Ao chamar de anglo-saxônica, Sérgio referia-se a uma educação do self-government, em que a iniciativa, a vontade criadora, a responsabilidade e o autodomínio seriam determinados pela organização do sistema escolar na forma da gestão de uma cidade ou de um município (SÉRGIO, 1915).
} 
Por fim, salientamos que foi possível perceber, ao realizar esta pesquisa, que os anos da Primeira República em Portugal foram bastante significativos no pulsar das ideias progressistas e pedagógicas. Entretanto, com a instituição de um Estado ditatorial não foram implementadas, mas ficaram arrefecidas e permaneceram na clandestinidade por quase quatro décadas. Em estado de arrefecimento se mantiveram, após a Segunda Guerra, quando a Europa respirava ares de incerteza, mas, em Portugal, a Ditadura seguia firme sem ares de novo respiro. Por fim, salientamos que hoje estamos diante de um passado histórico marcado por relações subjetivas entre a terra e a escola que ainda merecem ser estudadas para a melhor compreensão de questões adjacentes.

\section{Referências}

ARAUJO, Helena Costa. Pioneiras na educação: as professoras primárias na viragem do século (1870-1933). Porto: Afrontamento, 2000.

CARNEIRO LEÃO, Antônio. A sociedade rural: seus problemas e sua educação. Rio de Janeiro: A Noite, 1939.

CARNEIRO LEÃO, Antônio. O sentido da evolução cultural no Brasil. Rio de Janeiro: Edição do Ministério das Relações Exteriores, 1946.

CUNHAL, Álvaro. A questão agrária em Portugal. Rio de Janeiro: Civilização Brasileira, 1968.

DEWEY, John. Democracy and education: an introduction to the philosophy of education. New York: The Macmillan Company, 1916.

FERRIÈRE, Adolfo. Transformemos a escola: apêlo aos pais e às autoridades. Paris: Livraria Francesa e Estrangeira, 1928.

GIL, Antônio Carlos. Métodos e técnicas de pesquisa social. 5 ed. São Paulo: Atlas, 1999.

GONÇALVES; José Augusto. Educação cívica segundo Antônio Sérgio: sua actualidade. Lisboa: INSCOOP, 2003.

HESPANHA, Pedro. Com os pés na terra: práticas fundiárias da população rural portuguesa. Porto: Afrontamento, 1994. 
NÓVOA, Antônio. Portugal e o Estado Novo. In: PROENÇA, Maria Cândida (org.). História: o estado novo, materiais para professores. Lisboa: Instituto de Inovação Educacional, 1997.

NÓvOA, António. A educação cívica de António Sérgio vista a partir da Escola da Ponte (ou vice-versa). In: CANÁRIO, Rui; MATOS, Filomena; TRINDADE, Rui (orgs.). Escola da Ponte: defender a escola pública. Porto: Prodefinições, 2004.

PINTASSILGO, Joaquim. República e formação de cidadãos: a educação cívica nas escolas primárias da Primeira República Portuguesa. Lisboa: Colibri, 1998.

SÉRGIO, António; Educação Cívica. 4 a edição. Edição do Centenário. Cases: Lisboa, 2015.

SÉRGIO, António. Da natureza da afecção. Revista Americana, Rio de Janeiro, ano 4, n. 9, 1913.

SÉRGIO, António; Educação cívica. 4 ed. Lisboa: Cases, 1915.

SÉRGIO, António. Manual de instrução agrícola na escola primária. Porto: Renascença, 1916.

SÉRGIO, António. A sketch of the history of Portugal. Lisboa: Seara Nova, 1928.

SÉRGIO, António. Sobre a reforma do legislativo. Seara Nova, Lisboa, n. 292, mar. 1932.

SÉRGIO, António. Sobre educação primária e infantil. Lisboa: Inquérito, 1939.

SÉRGIO, António. Confissões de um cooperativista. Lisboa: Inquérito, 1948.

Recebido em: 17/04/2019

Aprovado em: 12/07/2019

Universidade do Estado de Santa Catarina - UDESC

Centro de Ciências Humanas e da Educação - FAED

Revista PerCursos

Volume 20 - Número 43 - Ano 2019

revistapercursos@gmail.com 